\title{
CORRECTION
}

\section{Correction to: Hail suppression effectiveness for varying solubility of natural aerosols in water}

\author{
Nemanja Kovačević ${ }^{1}$ (D)
}

Published online: 16 April 2018

(C) Springer-Verlag GmbH Austria, part of Springer Nature 2018

\section{Correction to: Meteorology and Atmospheric Physics https://doi.org/10.1007/s00703-018-0587-4}

Because of a production error, the black line in Fig. 13c is incorrect. The correct Fig. 13c is shown below.

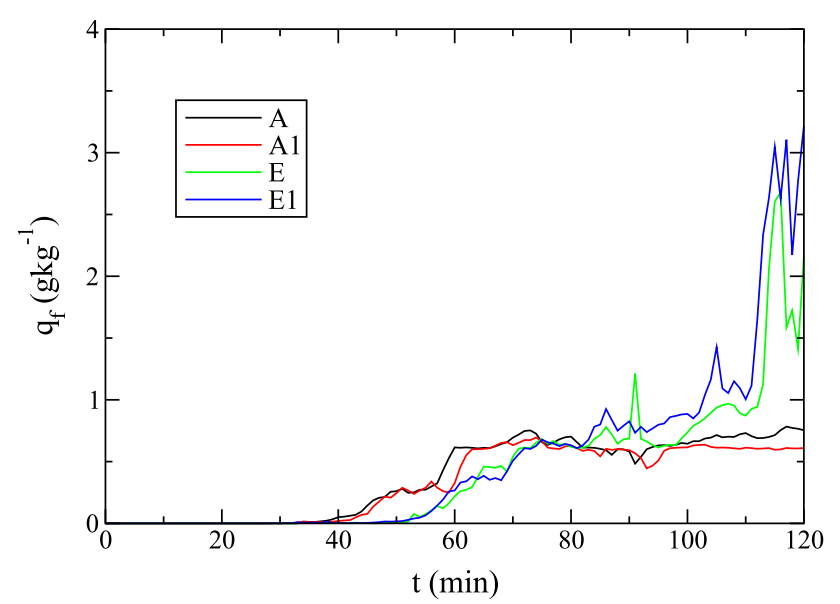

The original article can be found online at https://doi.org/10.1007/ s00703-018-0587-4.

Nemanja Kovačević

nemanja@ff.bg.ac.rs

1 Faculty of Physics, Institute of Meteorology, University of Belgrade, 16 Dobračina, 11000 Belgrade, Serbia 